Pacific Journal of Mathematics

A NOTE ON HYPONORMAL OPERATORS 


\section{A NOTE ON HYPONORMAL OPERATORS}

\section{SterLing K. Berberian}

The last exercise in reference [4] is a question to which I did not know the answer: does there exist a hyponormal $\left(T T^{*} \leqq T^{*} T\right)$ completely continuous operator which is not normal? Recently Tsuyoshi Andô has answered this question in the negative, by proving that every hyponormal completely continuous operator is necessarily normal ([1]). The key to Andô's solution is a direct calculation with vectors, showing that a hyponormal operator $T$ satisfies the relation $\left\|T^{n}\right\|=\|T\|^{n}$ for every positive integer $n$ (for "subnormal" operators, this was observed by P. R. Halmos on page 196 of [6]). It then follows, from Gelfand's formula for spectral radius, that the spectrum of $T$ contains a scalar $\mu$ such that $|\mu|=\|T\|$ (see [9], Theorem 1.6.3.).

The purpose of the present note is to obtain this result from another direction, via the technique of approximate proper vectors ([3]); $i_{n}$ this approach, the nonemptiness of the spectrum of a hyponormal operator $T$ is made to depend on the elementary case of a self-adjoint operator, and a simple calculation with proper vectors leads to a scalar $\mu$ in the spectrum of $T$ such that $|\mu|=\|T\|$. This is the Theorem below, and its Corollaries 1 and 2 are due also to Andô. In the remaining corollaries, we note several applications to completely continuous operators.

We consider operators (=continuous linear mappings) defined in a Hilbert space. As in [3], the spectrum of an operator $T$ is denoted $s(T)$, and the approximate point spectrum is $a(T)$. We note for future use that every boundary point of $s(T)$ belongs to $a(T)$; see, for example, ([4], hint to Exercise VIII. 3.4).

Lemma 1. Suppose $T$ is a hyponormal operator, with $\|T\| \leqq 1$, and let $\mathscr{M}$ be the set of all vectors which are fixed under the operator $T T^{*}$. Then,

(i) $\mathscr{C}$ is a closed linear subspace,

(ii) the vectors in $\mathscr{M}$ are fixed under $T^{*} T$,

(iii) $\mathscr{M}$ is invariant under $T$, and

(iv) the restriction of $T$ to $\mathscr{C}$ is an isometric operator in $\mathscr{K}$.

Proof. Since $\mathscr{A}=\left\{x: T T^{*} x=x\right\}$ is the null space of $I-T T^{*}$, it is a closed linear subspace. The relation $T T^{*} \leqq T^{*} T \leqq I$ implies $0 \leqq I-T^{*} T \leqq I-T T^{*}$, and from this it is clear that the null space of $I-T T^{*}$ is contained in the null space of $I-T^{*} T$. That is, $T T^{*} x=x$

Received February 27, 1962. 
implies $T^{*} T x=x$. This proves (ii). (Alternatively, given $T T^{*} x=x$, one can calculate directly that $\left\|T^{*} T x-x\right\|^{2} \leqq 0$.) If $x \in \mathscr{C}$, that is if $T T^{*} x=x$, then the calculation $T T^{*}(T x)=T\left(T^{*} T x\right)=T x$ shows that $T x \in \mathscr{C l}$; moreover, $\|T x\|^{2}=\left(T^{*} T x \mid x\right)=\|x\|^{2}$.

LEMMA 2. Every isometric operator has an approximate proper value of absolute value 1.

Proof. Let $U$ be an isometric operator in a nonzero Hilbert space. Suppose first that the spectrum of $U$ contains 1 ; since $\|U\|=1$, it follows that 1 is a boundary point of $s(U)$ (see [4], part (ix) of Exercise VII. 3. 12), hence 1 is an approximate proper value for $U$.

If the spectrum of $U$ does not contain 1 , that is if $I-U$ is invertible, we may form the Cayley transform $A$ of $U$; thus,

$$
A=i(I+U)(I-U)^{-1}=i(I-U)^{-1}(I+U) .
$$

Using the hypothesis $U^{*} U=I$, let us show that $A$ is self-adjoint. Leftmultiplying the relation $(I-U) A=i(I+U)$ by $U^{*}$, we have $\left(U^{*}-I\right)$ $A=i\left(U^{*}+I\right)$, thus $(I-U)^{*} A=-i(I+U)^{*}$. Since $(I-U)^{*}$ is invertible, with inverse $\left[(I-U)^{-1}\right]^{*}$, we have

$$
A=-i\left[(I-U)^{-1}\right]^{*}(I+U)^{*}=-i\left[(I+U)(I-U)^{-1}\right]^{*}=A^{*} .
$$

It follows that the operators $A+i I$ and $A-i I$ are invertible, and solving the relation $(I-U) A=i(I+U)$ for $U$, we have

$$
U=(A-i I)(A+i I)^{-1}=(A+i I)^{-1}(A-i I) .
$$

Incidentally, since $U$ is the product of invertible operators, we conclude that $U$ is unitary.

Since $A$ is self-adjoint, we know from an elementary argument that the approximate point spectrum of $A$ is non empty ([7], Theorem 34.2). Let $\alpha \in a(A)$, and let $x_{n}$ be a sequence of unit vectors such that $\left\|A x_{n}-\alpha x_{n}\right\| \rightarrow 0$. Define $\mu=(\alpha+i)^{-1}(\alpha-i)$; since $\alpha$ is real, $\mu$ has absolute value 1 . It will suffice to show that $\mu$ is an approximate proper value for $U$; indeed, $\left\|(U-\mu I) x_{n}\right\| \rightarrow 0$ results from the calculation

$$
\begin{aligned}
U-\mu I & =(A+i I)^{-1}(A-i I)-(\alpha+i)^{-1}(\alpha-i) I \\
& =(\alpha+i)^{-1}(A+i I)^{-1}[(\alpha+i)(A-i I)-(\alpha-i)(A+i I)] \\
& =2 i(\alpha+i)^{-1}(A+i I)^{-1}(A-\alpha I),
\end{aligned}
$$

the fact that $\left\|(A-\alpha I) x_{n}\right\| \rightarrow 0$, and the continuity of the operator $2 i(\alpha+i)^{-1}(A+i I)^{-1}$.

Incidentally, if $U$ is an isometric operator such that the spectrum of $U$ excludes some complex number $\mu$ of absolute value 1 , then $\mu^{-1} U$ 
is an isometric operator whose spectrum excludes 1 . The proof of Lemma 2 then shows that $\mu^{-1} U$ is unitary, hence so is $U$. In other words: the spectrum of a nonnormal isometry must include the unit circle $|\mu|=1$; indeed, Putnam has shown that the spectrum is the unit disc $|\mu| \leqq 1([8 \mid$, Corollary 1$)$. The latter result is also an immediate consequence of ([5], Lemma 2.1), and the fact that the spectrum of any unilateral shift operator is the unit disc.

THEOREM. (Andô) Every hyponormal operator $T$ has an approximate proper value $\mu$ such that $|\mu|=\|T\|$.

Proof. We may assume $\|T\|=1$ without loss of generality. Since $T T^{*} \geqq 0$ and $\left\|T T^{*}\right\|=1$, we know that 1 is an approximate proper value for $T T^{*}$. Since the property of hyponormality is preserved under *-isomorphism, we may assume, after a change of Hilbert space, that 1 is a proper value for $T T^{*}$ ([3], Theorem 1). Form the nonzero closed linear subspace $\mathscr{C}=\left\{x: T T^{*} x=x\right\}$; according to Lemma 1 , $\mathscr{C}$ is invariant under $T$, and the restriction of $T$ to $\mathscr{C}$ is an isometric operator $U$ in the Hilbert space $\mathscr{C}$. By Lemma 2, $U$ has an approximate proper value $\mu$ of absolute value 1 . Let $x_{n}$ be any sequence of unit vectors in $\mathscr{C}$ such that $\left\|U x_{n}-\mu x_{n}\right\| \rightarrow 0$. Since $U x_{n}=T x_{n}$, obviously $\mu$ is an approximate proper value for $T$, and $|\mu|=1=\|T\|$.

CoRollary 1. A generalized nilpotent hyponormal operator is necessarily zero.

Proof. If $T$ is hyponormal, then $s(T)$ contains a scalar $\mu$ such that $|\mu|=\|T\|$. For every positive integer $n$, it follows that $s\left(T^{n}\right)$ contains $\mu^{n}$ (see [7], Theorem 33.1); then $\|T\|^{n}=|\mu|^{n}=\left|\mu^{n}\right| \leqq\left\|T^{n}\right\| \leqq\|T\|^{n}$, and so $\left\|T^{n}\right\|=\|T\|^{n}$. If moreover $T$ is a generalized nilpotent, that is if $\lim \left\|T^{n}\right\|^{1 / n}=0$, then $\|T\|=0$.

CoRollary 2. If $T$ is a completely continuous hyponormal operator, then $T$ is normal.

Proof. The proof to be given is essentially the same as Andô's. The proper subspaces of $T$ are mutually orthogonal, and reduce $T$ ([4], Exercise VII. 2.5). Let $\mathscr{C}$ be the smallest closed linear subspace which contains every proper subspace of $T$, and let $\mathscr{N}=\mathscr{C}^{\perp}$; clearly $\mathscr{N}$ reduces $T$, and the restriction $T / \mathscr{N}$ is a completely continuous hyponormal operator in $\mathscr{N}$ ([4], Exercise VI. 9.18). If the spectrum of $T / \mathscr{N}$ were different from $\{0\}$, it would have a nonzero boundary point $\mu$, hence $\mu$ would be a proper value for $T / \mathscr{N}$ (see [4], Theorem VIII. 3.2); this is impossible since $\mathscr{N}^{\perp}=\mathscr{C}$ already contains every proper vector for $T$. 
We conclude from the Theorem that $T / \mathscr{N}=0$, and this forces $\mathscr{N}=\{0\}$ (recall that $\mathscr{N}^{\perp}$ contains the null space of $T$ ). Thus, the proper subspaces of $T$ are a total family, hence $T$ is normal by ([4], Exercise VII. 2.5).

Suppose $T$ is a normal operator whose spectrum (a) has empty interior, and (b) does not separate the complex plane. Wermer has shown that the invariant subspaces of $T$ reduce $T$ ([10], Theorem 7). It is well known that the conditions (a) and (b) are fulfilled by the spectrum of any completely continuous operator. In particular: if $T$ is a completely continuous normal operator, then every invariant subspace of $T$ reduces $T$. A more elementary proof of this may be based on Corollary 2:

COROLlaRY 3. If $T$ is a completely continuous normal operator, and $\mathscr{N}$ is a closed linear subspace invariant under $T$, then $\mathscr{N}$ reduces $T$.

Proof. Indeed, it suffices to assume that $T$ is hyponormal and $\mathscr{N}$ is an invariant subspace such that $T / \mathscr{N}$ is completely continuous. Since $T / \mathscr{N}$ is hyponormal ([4], Exercise VI. 9.10), it follows from Corollary 2 that $T / \mathscr{N}$ is normal, hence $\mathscr{N}$ reduces $T$ by ([4], Exercise VI. 9.9).

Quoting ([4], Theorem VII. 3.1), we have:

COROLLARY 4. If $T$ is a hyponormal operator, then

$$
\|T\|=L U B\{|(T x \mid x)|:\|x\| \leqq 1\} .
$$

Incidentally, if $T$ is hyponormal, it is clear from Corollary 4 that $\left\|T^{*}\right\|=L U B\left\{\left|\left(T^{*} x \mid x\right)\right|:\|x\| \leqq 1\right\}$.

CoROLlaRY 5. If the completely continuous operator $T$ is seminormal in the sense of [8], then $T$ is normal.

Proof. The definition of semi-normality is that either $T T^{*} \leqq T^{*} T$ or $T T^{*} \geqq T^{*} T$, in other words, either $T$ or $T^{*}$ is hyponormal; since both are completely continuous (see [4], Exercise VIII. 1.6), our assertion follows from Corollary 2.

Let us say that an operator $T$ is nearly normal in case $T$ commutes with $T^{*} T$. The structure of nearly normal operators has been determined by Brown, and it is a consequence of his results that a completely continuous nearly normal operator is in fact normal (see the concluding remarks in [5]). This may also be proved as follows. An elementary calculation with square roots shows that a nearly normal operator is hyponormal (see [2], proof of Corollary 1 of Theorem 8); assuming also complete continuity and citing Corollary 2, we have; 
COROLLARY 6. If $T$ is a completely continuous nearly normal operator, then $T$ is normal.

Finally,

CoRollary 7. If $S=T+\lambda I$, where $T$ is a completely continuous operator, and if $S$ is hyponormal, then $S$ is normal.

Proof. Since $S$ is hyponormal, so is $T$ ([4], hint to Exercise VII. 1.6), hence $T$ is normal by Corollary 2 ; therefore $S$ is normal. So to speak, the $C^{*}$-algebra of all operators of the from $T+\lambda I$, with $T$ completely continuous, is of "finite class".

We close with an elementary remark about the adjoint of a hyponormal operator: if $T$ is hyponormal, then $s\left(T^{*}\right)=a\left(T^{*}\right)$. For, suppose $\lambda$ does not belong to $a\left(T^{*}\right)$, and let $\mu=\lambda^{*}$. Then, $(T-\mu I)^{*}=T^{*}-\lambda I$ is bounded below ([4], Exercise VII. 3.8), and since $T-\mu I$ is also hyponormal, the relation $(T-\mu I)(T-\mu I)^{*} \leqq(T-\mu I)^{*}(T-\mu I)$ shows that $T-\mu I$ is also bounded below. Then $T-\mu I$ is invertible ([4], Exercise VI. 8.11), hence so is $T^{*}-\lambda I$, thus $\lambda$ does not belong to $s\left(T^{*}\right)$.

\section{REFERENCES}

1. T. Andô, Forthcoming paper in Proc. Amer. Math. Soc.

2. S. K. Berberian, Note on a theorem of Fuglede and Putnam, Proc. Amer. Math. Soc., 10 (1959), 175-182.

3. — Approximate proper vectors, Proc. Amer. Math. Soc., 13 (1962), 111-114.

4. - Introduction to Hilbert space, Oxford University Press, New York, 1961.

5. A. Brown, On a class of operators, Proc. Amer. Math. Soc., 4 (1953), 723-728.

6. P. R. Halmos, Commutators of operators, II., Amer. J. Math., 76 (1954), 191-198.

7. - Introduction to Hilbert space and the theory of spectral multiplicity, Chelsea, New York, 1951.

8. C. R. "Putnam, On semi-normal operators, Pacific J. Math., 7 (1957), 1649-1652.

9. C. E. Rickart, General theory of Banach algbras, D. van Nostrand, New York, 1960.

10. J. Wermer, On invariant subspaces of normal operators, Proc. Amer. Math. Soc., 3 (1952), 270-277.

State University of IowA 



\section{PACIFIC JOURNAL OF MATHEMATICS}

\section{EDITORS}

\author{
Ralph S. Phillips \\ Stanford University \\ Stanford, California \\ M. G. Arsove \\ University of Washington \\ Seattle 5 , Washington
}

\author{
A. L. Whiteman \\ University of Southern California \\ Los Angeles 7, California \\ Lowell J. Paige \\ University of California \\ Los Angeles 24, California
}
E. F. BECKENBACH
D. DERRY
ASSOCIATE EDITORS
T. M. CHERRY
M. OHTSUKA
H. L. ROYDEN
E. G. STRAUS
E. SPANIER
F. WOLF

\section{SUPPORTING INSTITUTIONS}

\author{
UNIVERSITY OF BRITISH COLUMBIA \\ CALIFORNIA INSTITUTE OF TECHNOLOGY \\ UNIVERSITY OF CALIFORNIA \\ MONTANA STATE UNIVERSITY \\ UNIVERSITY OF NEVADA \\ NEW MEXICO STATE UNIVERSITY \\ OREGON STATE UNIVERSITY \\ UNIVERSITY OF OREGON \\ OSAKA UNIVERSITY \\ UNIVERSITY OF SOUTHERN CALIFORNIA
}

\author{
STANFORD UNIVERSITY \\ UNIVERSITY OF TOKYO \\ UNIVERSITY OF UTAH \\ WASHINGTON STATE UNIVERSITY \\ UNIVERSITY OF WASHINGTON \\ AMERICAN MATHEMATICAL SOCIETY \\ CALIFORNIA RESEARCH CORPORATION \\ SPACE TECHNOLOGY LABORATORIES \\ NAVAL ORDNANCE TEST STATION
}

Mathematical papers intended for publication in the Pacific Journal of Mathematıcs should be typewritten (double spaced), and the author should keep a complete copy. Manuscripts may be sent to any one of the four editors. All other communications to the editors should be addressed to the managing editor, L. J. Paige at the University of California, Los Angeles 24, California.

50 reprints per author of each article are furnished free of charge; additional copies may be obtained at cost in multiples of 50 .

The Pacific Journal of Mathematics is published quarterly, in March, June, September, and December. Effective with Volume 13 the price per volume (4 numbers) is $\$ 18.00$; single issues, $\$ 5.00$. Special price for current issues to individual faculty members of supporting institutions and to individual members of the American Mathematical Society: $\$ 8.00$ per volume; single issues $\$ 2.50$. Back numbers are available.

Subscriptions, orders for back numbers, and changes of address should be sent to Pacific Journal of Mathematics, 103 Highland Boulevard, Berkeley 8, California.

Printed at Kokusai Bunken Insatsusha (International Academic Printing Co., Ltd.), No. 6, 2-chome, Fujimi-cho, Chiyoda-ku, Tokyo, Japan.

PUBLISHED BY PACIFIC JOURNAL OF MATHEMATICS, A NON-PROFIT CORPORATION

The Supporting Institutions listed above contribute to the cost of publication of this Journal, but they are not owners or publishers and have no responsibility for its content or policies. 


\section{Pacific Journal of Mathematics}

\section{Vol. 12 , No. 4 \\ April, 1962}

Tsuyoshi Andô, On fundamental properties of a Banach space with a cone ..... . 1163

Sterling K. Berberian, A note on hyponormal operators ................ 1171

Errett Albert Bishop, Analytic functions with values in a Frechet space . . . . . . . 1177

(Sherman) Elwood Bohn, Equicontinuity of solutions of a quasi-linear equation ............................................ 1193

Andrew Michael Bruckner and E. Ostrow, Some function classes related to the class of convex functions . . . . . . . . . . . . . . . . . . . . . . . . 1203

J. H. Curtiss, Limits and bounds for divided differences on a Jordan curve in the complex domain . . ................................. 1217

P. H. Doyle, III and John Gilbert Hocking, Dimensional invertibility . . . . . . . . 1235

David G. Feingold and Richard Steven Varga, Block diagonally dominant matrices and generalizations of the Gerschgorin circle theorem ................. 1241

Leonard Dubois Fountain and Lloyd Kenneth Jackson, A generalized solution of the boundary value problem for $y^{\prime \prime}=f\left(x, y, y^{\prime}\right) \ldots \ldots \ldots \ldots \ldots \ldots \ldots \ldots \ldots$

Robert William Gilmer, Jr., Rings in which semi-primary ideals are primary. . . . . 1273

Ruth Goodman, K-polar polynomials .......................... 1277

Israel Halperin and Maria Wonenburger, On the additivity of lattice completeness ........................................... 1289

Robert Winship Heath, Arc-wise connectedness in semi-metric spaces . . . . . . . . 1301

Isidore Heller and Alan Jerome Hoffman, On unimodular matrices . . . . . . . . . . . 1321

Robert G. Heyneman, Duality in general ergodic theory . . . . . . . . . . . . . . . 1329

Charles Ray Hobby, Abelian subgroups of p-groups . . . . . . . . . . . . . . . 1343

Kenneth Myron Hoffman and Hugo Rossi, The minimum boundary for an analytic

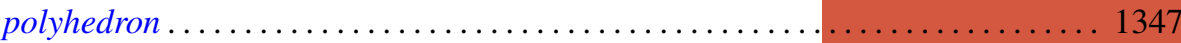

Adam Koranyi, The Bergman kernel function for tubes over convex cones ........ 1355

Pesi Rustom Masani and Jack Max Robertson, The time-domain analysis of a continuous parameter weakly stationary stochastic proces.

William Schumacher Massey, Non-existence of almost-complex structures on

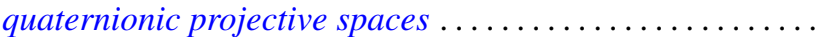

Deane Montgomery and Chung-Tao Yang, A theorem on the action of $\mathrm{SO}(3) \ldots . .1385$

Ronald John Nunke, A note on Abelian group extensions . . . . . . . . . . . . . 1401

Carl Mark Pearcy, A complete set of unitary invariants for operators generating finite $W^{*}$-algebras of type $I$

Edward C. Posner, Integral closure of rings of solutions of linear differential equations.

Duane Sather, Asymptotics. III. Stationary phase for two parameters with an application to Bessel functions.

J. Śladkowska, Bounds of analytic functions of two complex variables in domains

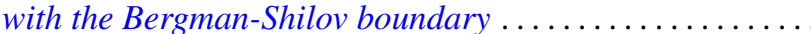

Joseph Gail Stampfli, Hyponormal operators .

George Gustave Weill, Some extremal properties of linear combinations of kernels

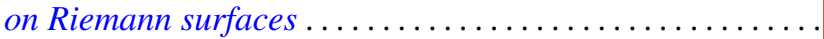

